\section{High intravitreal TGF- $\beta 1$ and MMP-9 levels in eyes with retinal vein occlusion}

R Tuuminen ${ }^{1}$ and S Loukovaara ${ }^{2}$

\begin{abstract}
Purpose Vascular endothelial growth factor is a leading target to reduce macular oedema and improve visual acuity in patients with retinal vein occlusion (RVO), whereas the role of vascular destabilizing and fibroproliferative transforming growth factor (TGF)- $\beta 1$ and matrix metalloproteinases (MMP)-2 and -9 in pathological manifestations of RVO is anticipated but less studied. Methods Undiluted vitreous samples were collected from three central RVO and one branch RVO eyes, all with neovascularization and fibrosis-related sight-threatening complications of RVO. Undiluted vitreous samples of 40 eyes operated due to nonischemic condition either macular hole or pucker were used as controls. Growth factor and protease concentrations were measured by ELISA and gelatin zymography.

Results Vitreous concentrations of TGF- $\beta 1$ $(92.0 \pm 17.4 \mathrm{pg} / \mathrm{ml}$ vs $18.3 \pm 27.0 \mathrm{pg} / \mathrm{ml}$, mean \pm SD; $P=0.002$ ) and MMP-9 $(847.9 \pm 1196.4 \mathrm{AU} / \mathrm{ml}$ vs $87.7 \pm 174.0 \mathrm{AU} / \mathrm{ml}$; $P=0.010)$ were higher in the eyes with ischemic RVO than in the controls. Conclusions High intravitreal levels of TGF- $\beta 1$ and MMP-9 are found in RVO eyes having neovascular and fibrosis manifestation. Further studies are warranted to elucidate whether targeting TGF- $\beta 1$ and MMP-9 could be beneficial in patients with ischemic RVO.
\end{abstract}

Eye (2014) 28, 1095-1099; doi:10.1038/eye.2014.137; published online 20 June 2014

\section{Introduction}

Retinal vein occlusion (RVO) is the second most common retinal vascular disorder after diabetic retinopathy and a frequent cause of visual loss. ${ }^{1}$ The pathogenesis of RVO is multifactorial. ${ }^{2-4}$
RVO disturbs retinal blood circulation and is associated with a variable degree of capillary non-perfusion and hypoxia in the inner retina. ${ }^{5-7}$ These changes lead to severe posterior segment complications such as macular oedema, vitreous haemorrhage, neovascularization, and fibrovascular tissue formation.

Transforming growth factor (TGF)- $\beta$ is a cytokine that has been implicated in permeability, inflammation, and fibroproliferation by controlling cytoskeletal remodelling, barrier breakdown, and mesenchymal transition of microvascular endothelium (EC). ${ }^{8-10}$ Furthermore, TGF- $\beta$ mediates contraction of preretinal membranes. ${ }^{11}$ TGF- $\beta$ is induced in the vitreous in proliferative diabetic retinopathy and proliferative vitreoretinopathy. ${ }^{12-14}$ Matrix

metalloproteinases (MMPs) are calcium- or zinc-dependent extracellular proteolytic enzymes that have a role in degrading and remodelling of extracellular matrix in various physiological and pathological conditions including ischemic vitreoretinal eye diseases. ${ }^{15,16}$ Especially, MMP-2 and -9 are linked to a variety of EC functions, including proliferation, differentiation, and angiogenesis. ${ }^{17-19}$

Until recently, only a limited evidence of any efficient treatment options existed for branch and central RVO (CRVO). ${ }^{20,21}$ In recent prospective randomized clinical trials, regular anti-vascular endothelial growth factor (VEGF) treatment significantly decreased macular oedema and increased best corrected visual acuity in patients with RVO compared with sham controls. ${ }^{22-25}$ On the basis of these studies, intravitreal injections of anti-VEGF agents are now emerging as a part of the first-line treatment of RVO. The anti-VEGF therapy,
${ }^{1}$ Department of Ophthalmology, Helsinki University Central Hospital, University of Helsinki, Helsinki, Finland

${ }^{2}$ Unit of Vitreoretinal Surgery, Department of Ophthalmology, Helsinki University Central Hospital, Helsinki, Finland

Correspondence: R Tuuminen, Department of Ophthalmology, Helsinki University Central Hospital, University of Helsinki, Haartmaninkatu 4 C, FI-00290 Helsinki, Finland Tel: +358 50 4288045; Fax: +358 947175100 . E-mail: raimo.tuuminen@ hus.fi

Received: 15 September 2013

Accepted in revised form: 15 May 2014 Published online: 20 June 2014 
however, might have detrimental long-term local side-effects in the retina. ${ }^{26}$ Therefore, development of alternative treatment modalities for RVO remains a priority.

In this study, we performed vitrectomy for the management of neovascularization and fibrosis-related sight-threatening complications of ischemic RVO.

We measured the vitreous concentrations of the TGF- $\beta 1$, MMP-2, and -9, those of are anticipated but undefined in the pathogenesis of ischemic RVO.

\section{Materials and methods}

\section{Study design}

This was a prospective controlled observational study. Patients were admitted for primary vitrectomy due to management of sight-threatening complications of eyes with RVO to the Vitreoretinal Surgery Unit, Helsinki University Central Hospital, Helsinki, Finland. The study was conducted according to the tenets of the Declaration of Helsinki, and it was approved by the Institutional Review Board of Helsinki University Central Hospital.

\section{Surgery}

Undiluted vitreous samples (up to $1000 \mu \mathrm{l}$ ) were collected at the start of the pars plana vitrectomy (20 or $23 \mathrm{G}$, Accurus, Alcon Instruments, Inc., Fort Worth, TX, USA) without an infusion of artificial fluid. The samples were collected by manual aspiration into a syringe via the vitrectomy with the cutting function activated. Samples were transferred into sterile $1.5 \mathrm{ml}$ Eppendorf tubes (Eppendorf, Freemont, CA, USA) and immediately frozen at $-70{ }^{\circ} \mathrm{C}$ until laboratory analysis.

\section{Patients and controls}

A total of three CRVO and one branch RVO patient were vitrectomized because of fibrovascular tissue formationrelated complications of RVO. All RVO eyes had secondary neovascularization of the disc or along the vessels elsewhere and some fibrosis formation. None of the study subjects had diabetes or previous ophthalmologic history before RVO. Intravitreal injections of anti-VEGF were not used in the study eyes pre-vitrectomy. The control group consisted of 40 eyes operated due to non-ischemic conditions either a quiescent idiopathic macular hole or pucker.

\section{Protein measurement}

Vitreous total protein concentrations $(\mathrm{mg} / \mathrm{ml})$ were measured to evaluate the nonspecific effects of blood-retina barrier breakdown and to compare undiluted vitreous catch between study groups using a bicinchonic acid protein assay kit (Pierce, Thermo Scientific, Rockford, IL, USA). Each vitreous sample was diluted with sterile water before the measurement, thus leading to sample dilutions between 1:30 and 1:50 in the bicinchonic acid reaction mix that minimized any effects from blood (iron) or other interfering substances.

\section{Determination of vitreous biomarkers}

Total TGF- $\beta 1$ levels were measured using Quantikine ELISA kit (DB100B, R\&D Systems, Minneapolis, MN, USA). Latent forms of TGF- $\beta 1$ were acid-activated before the assay according to the manufacturer's instructions. Gelatin zymography was performed to evaluate the relative levels and activation ratios of MMP-2 and -9 zymogen (pro- and total-MMP-2 and MMP-9) in the vitreous samples. To analyse the gelatinolytic proteins, aliquots of vitreous samples were subjected to gelatin zymography essentially as described. ${ }^{27}$ The polypeptides of the samples were dissolved in non-reducing Laemmli sample buffer and separated by SDS-PAGE using $10 \%$ polyacrylamide gels containing $1 \mathrm{mg} / \mathrm{ml}$ of gelatin. After electrophoresis, the gels were washed twice with $50 \mathrm{mM}$ Tris- $\mathrm{HCl}$, pH 7.6, containing $5 \mathrm{mM} \mathrm{CaCl}_{2}, 1 \mu \mathrm{M} \mathrm{ZnCl}_{2}$, and $2.5 \%$ Triton $\mathrm{X}-100(\mathrm{v} / \mathrm{v})$ for $15 \mathrm{~min}$ to remove SDS, followed by a brief rinsing in washing buffer without Triton X-100. The gels were then incubated at $37^{\circ} \mathrm{C}$ for $12-24 \mathrm{~h}$ in $50 \mathrm{mM}$ Tris- $\mathrm{HCl}$ buffer containing $5 \mathrm{mM} \mathrm{CaCl}_{2}$, $1 \mu \mathrm{M} \mathrm{ZnCl}_{2}, 1 \%$ Triton X-100, and 0.02\% $\mathrm{NaN}_{3}, \mathrm{pH}$ 7.6. The gels were stained with Coomassie Brilliant Blue R250, followed by destaining with $10 \%$ acetic acid and 5\% methanol. The zymogen gels were later scanned by an image scanner, and the areas of clear bands corresponding to MMP-2 and MMP-9 activity were calculated using the ImageJ software (v1.42q, NIH, Bethesda, MD, USA, http://rsb.info.nih.gov/nih-image/) on non-altered original TIFF files in the 8 bit dynamic range of signal intensities. The values are reported in arbitrary units (AU/ml).

\section{Statement of ethics}

We certify that all applicable institutional and governmental regulations concerning the ethical use of human volunteers were followed during this research.

\section{Statistical analysis}

All data are mean \pm SD and were analysed with SPSS 15.0 (SPSS Inc., Somers, NY, USA). For two-group comparisons, a non-parametric Mann-Whitney U-test was used. Effect of age was controlled with the analysis 
of covariance. $P \leq 0.05$ was considered statistically significant.

\section{Results}

\section{Study patients}

Significant differences between the RVO and the control group were found for age $(P=0.018$; Table 1$)$ and best corrected visual acuity in $\log \operatorname{MAR}(P=0.033$; Table 1$)$.

\section{Intravitreal protein levels}

The intravitreal concentrations of TGF- $\beta 1$ ( $P=0.002$; Table 1) were significantly higher in eyes undergoing primary vitrectomy due to RVO than in the eyes with a macular hole or pucker. Moreover, gelatin zymography analysis revealed higher intravitreal proMMP-9 $(P=0.033$; Table 1$)$ and total MMP-9 $(P=0.010$; Table 1$)$ concentrations in eyes operated for ischemic RVO, whereas no significant difference was found in the concentrations of pro- or total MMP-2 (Table 1).

The analysis of covariance was performed to document whether found differences in the intravitreal levels were due to the age difference between the RVO and the control groups. When age was included as a covariate, intravitreal concentrations of TGF- $\beta 1$ $(P=0.002)$ and total MMP-9 $(P=0.015)$ were higher in RVO patients compared with controls (data not shown).

\section{Discussion}

In RVO, hypoxia induces expression and secretion of cytokines and growth factors that contribute to vascular instability and pro-inflammatory milieu, neovascularization, and fibroproliferation. ${ }^{28,29}$ Novel treatment modalities for the prevention of RVO complications are currently under active investigation.

Previous studies underscored concomitant overexpression of ischemia-regulated erythropoietin and VEGF in RVO, which were linked to pathological neovascularization. ${ }^{30-32}$ Here, we focused on other potential factors that might lead to the retinal damage in RVO. TGF- $\beta$ and MMPs promote tissue remodelling and angiogenesis by EC cytoskeletal rearrangement and proteolysis of the EC basement membranes. High TGF- $\beta 1$ and $-\beta 2$ concentrations have been found in the aqueous humour of eyes operated for neovascular glaucoma secondary to CRVO but yet no intravitreal data of TGF levels in RVO is available. ${ }^{33}$ Moreover, elevated intravitreal levels of MMP-2 and -9 have been found in vitrectomized patients with proliferative diabetic retinopathy and other vitreoretinal diseases. ${ }^{34-37}$ These data included heterogeneous patient cohorts with only one CRVO patient. Congruent with this small piece of evidence, we now report elevated intravitreal TGF- $\beta 1$ and MMP-9 levels in eyes with ischemic RVO.

Regardless the number of eyes operated due to advanced complications of RVO was small, the study shows that intravitreal levels of TGF- $\beta 1$ and MMP-9 were significantly higher in ischemic RVO eyes compared with

Table 1 Clinical characteristics and intravitreal protein concentrations of the study population

\begin{tabular}{|c|c|c|c|}
\hline & Macular hole/pucker $(\mathrm{n}=40)$ & $R V O(\mathrm{n}=4)$ & P-value \\
\hline \multicolumn{4}{|l|}{ Clinical characteristics } \\
\hline Male/female & $14: 26$ & $2: 2$ & 0.646 \\
\hline Age (years) & $69.9 \pm 6.6$ & $53.2 \pm 14.9$ & $0.018^{\mathrm{a}}$ \\
\hline Hypertension & $18(45 \%)$ & $2(50 \%)$ & 0.877 \\
\hline Diastolic blood pressure $(\mathrm{mm} \mathrm{Hg})$ & $84.1 \pm 10.5$ & $88.0 \pm 12.1$ & 0.572 \\
\hline Systolic blood pressure $(\mathrm{mm} \mathrm{Hg})$ & $154.4 \pm 23.9$ & $156.2 \pm 43.5$ & 0.939 \\
\hline Body mass index $\left(\mathrm{kg} / \mathrm{m}^{2}\right)$ & $27.2 \pm 3.6$ & $28.4 \pm 4.9$ & 0.665 \\
\hline Smoking & $8(20 \%)$ & $2(50 \%)$ & 0.379 \\
\hline BCVA in LogMAR & $0.9 \pm 0.4$ & $1.8 \pm 0.5$ & $0.033^{\mathrm{a}}$ \\
\hline IOP & $15.6 \pm 4.3$ & $13.8 \pm 5.3$ & 0.539 \\
\hline Duration of RVO (months) & - & $11.2 \pm 17.2$ & - \\
\hline \multicolumn{4}{|l|}{ Intravitreal protein concentrations } \\
\hline Total protein $(\mathrm{mg} / \mathrm{ml})$ & $3.4 \pm 1.8$ & $3.6 \pm 1.1$ & 0.733 \\
\hline TGF- $\beta 1(\mathrm{pg} / \mathrm{ml})$ & $18.3 \pm 27.0$ & $92.0 \pm 17.4$ & $0.002^{\mathrm{a}}$ \\
\hline ProMMP-2 (AU/ml) & $3892.6 \pm 2516.3$ & $6527.8 \pm 3830.7$ & 0.167 \\
\hline Total MMP-2 (AU/ml) & $4021.8 \pm 2688.0$ & $7155.9 \pm 4447.6$ & 0.131 \\
\hline ProMMP-9 (AU /ml) & $87.7 \pm 174.0$ & $847.9 \pm 1196.4$ & $0.033^{\mathrm{a}}$ \\
\hline Total MMP-9 (AU/ml) & $113.9 \pm 229.7$ & $1183.3 \pm 1163.6$ & $0.010^{\mathrm{a}}$ \\
\hline
\end{tabular}

Abbreviations: BCVA, best corrected visual acuity; IOP, intraocular pressure; MMP, matrix metalloproteinase; RVO, retinal vein occlusion. Data are given as mean \pm SD. A non-parametric Mann-Whitney $U$-test was used for two-group comparisons.

aDenotes a statistically significant $(P<0.05)$ difference between the groups. 
non-ischemic controls. Comparability of total intravitreal protein concentrations in eyes of the study groups suggest increased de novo TGF- $\beta 1$ and MMP-9 production rather than leakage from blood because of inner blood-retinal barrier breakdown. TGF- $\beta 1$ and MMP-9 overexpression might be important in fibrovascular activity in RVO eyes.

In spite of recent advances in the treatment for ischemic retinal disorders, the demand for nontoxic efficient treatment modalities remain topical. Further studies are warranted to elucidate whether inhibition of TGF- $\beta 1$ and MMP-9 has a potential as an alternative or adjunct therapy together with anti-VEGF treatment and whether it might improve the prognosis of RVO to a greater extent than anti-VEGF therapies alone.

\section{Summary}

What was known before

- Intravitreal injections of anti-VEGF agents are emerging as a part of the first-line treatment of RVO.

- Recently published data, however, suggest that the anti-VEGF therapy might have detrimental long-term local side-effects in the retina.

- Therefore, development of alternative treatment modalities for RVO remains a priority.

What this study adds

- Levels of potent vascular destabilizing and fibroproliferative factors TGF- $\beta 1$ and MMP-9 were significantly higher in those eyes vitrectomized due to ischemic RVO compared with non-ischemic macular hole and pucker controls.

- Our novel data will encourage further studies to elucidate whether targeting TGF- $\beta 1$ and MMP-9 has a potential as an alternative or adjunct therapy together with anti-VEGF treatment and whether it might improve the prognosis of RVO to a greater extent than anti-VEGF therapies alone.

\section{Conflict of interest}

The authors declare no conflict of interest.

\section{Acknowledgements}

This study was supported by grants from the Finnish Eye Foundation, the Eye and Tissue Bank Foundation, the Mary and Georg C Ehrnrooth Foundation, the Nissi Foundation, and HUCH Clinical Research Grants (TKK4150 and TYH1325).

\section{References}

1 Rogers S, McIntosh RL, Cheung N, Lim L, Wang JJ, Mitchell $\mathrm{P}$ et al. The prevalence of retinal vein occlusion: pooled data from population studies from the United States,
Europe, Asia, and Australia. Ophthalmology 2010; 117(2): 313-319 e311.

2 Elman MJ, Bhatt AK, Quinlan PM, Enger C. The risk for systemic vascular diseases and mortality in patients with central retinal vein occlusion. Ophthalmology 1990; 97(11): 1543-1548.

3 Rath EZ, Frank RN, Shin DH, Kim C. Risk factors for retinal vein occlusions. A case-control study. Ophthalmology 1992; 99(4): 509-514.

4 Wong TY, Larsen EK, Klein R, Mitchell P, Couper DJ, Klein $\mathrm{BE}$ et al. Cardiovascular risk factors for retinal vein occlusion and arteriolar emboli: the Atherosclerosis Risk in Communities \& Cardiovascular Health studies. Ophthalmology 2005; 112(4): 540-547.

5 Laatikainen L, Kohner EM. Fluorescein angiography and its prognostic significance in central retinal vein occlusion. Br J Ophthalmol 1976; 60(6): 411-418.

6 Yoneya S, Saito T, Nishiyama Y, Deguchi T, Takasu M, Gil T et al. Retinal oxygen saturation levels in patients with central retinal vein occlusion. Ophthalmology 2002; 109(8): 1521-1526.

7 Hardarson SH, Stefansson E. Oxygen saturation in central retinal vein occlusion. Am J Ophthalmol 2010; 150(6): 871-875.

8 Behzadian MA, Wang XL, Windsor LJ, Ghaly N, Caldwell RB. TGF-beta increases retinal endothelial cell permeability by increasing MMP-9: possible role of glial cells in endothelial barrier function. Invest Ophthalmol Vis Sci 2001; 42(3): 853-859.

9 Zeisberg EM, Tarnavski O, Zeisberg M, Dorfman AL, McMullen JR, Gustafsson E et al. Endothelial-tomesenchymal transition contributes to cardiac fibrosis. Nat Med 2007; 13(8): 952-961.

10 Tuuminen R, Syrjala S, Krebs R, Keränen MA, Koli K, Abo-Ramadan U et al. Donor simvastatin treatment abolishes rat cardiac allograft ischemia/reperfusion injury and chronic rejection through microvascular protection. Circulation 2011; 124(10): 1138-1150.

11 Kita T, Hata Y, Arita R, Kawahara S, Miura M, Nakao S et al. Role of TGF-beta in proliferative vitreoretinal diseases and ROCK as a therapeutic target. Proc Natl Acad Sci USA 2008; 105(45): 17504-17509.

12 Connor Jr., TB, Roberts AB, Sporn MB, Danielpour D, Dart LL, Michels RG et al. Correlation of fibrosis and transforming growth factor-beta type 2 levels in the eye. J Clin Invest 1989; 83(5): 1661-1666.

13 Kita T, Hata Y, Kano K, Miura M, Nakao S, Noda Y et al. Transforming growth factor-beta2 and connective tissue growth factor in proliferative vitreoretinal diseases: possible involvement of hyalocytes and therapeutic potential of Rho kinase inhibitor. Diabetes 2007; 56(1): 231-238.

14 Gerhardinger C, Dagher Z, Sebastiani P, Park YS, Lorenzi M. The transforming growth factor-beta pathway is a common target of drugs that prevent experimental diabetic retinopathy. Diabetes 2009; 58(7): 1659-1667.

15 Sivak JM, Fini ME. MMPs in the eye: emerging roles for matrix metalloproteinases in ocular physiology. Prog Retin Eye Res 2002; 21(1): 1-14.

16 Feng Y, Wang Y, Pfister F, Hillebrands JL, Deutsch U, Hammes HP. Decreased hypoxia-induced neovascularization in angiopoietin-2 heterozygous knockout mouse through reduced MMP activity. Cell Physiol Biochem 2009; 23(4-6): 277-284. 
17 Iurlaro M, Loverro G, Vacca A, Cormio G, Ribatti D, Minischetti $\mathrm{M}$ et al. Angiogenesis extent and expression of matrix metalloproteinase-2 and -9 correlate with upgrading and myometrial invasion in endometrial carcinoma. Eur J Clin Invest 1999; 29(9): 793-801.

18 Das A, McLamore A, Song W, McGuire PG. Retinal neovascularization is suppressed with a matrix metalloproteinase inhibitor. Arch Ophthalmol 1999; 117(4): 498-503.

19 Gao H, Zhang J, Liu T, Shi W. Rapamycin prevents endothelial cell migration by inhibiting the endothelialto-mesenchymal transition and matrix metalloproteinase-2 and -9: an in vitro study. Mol Vis 2011; 17: 3406-3414.

20 McIntosh RL, Mohamed Q, Saw SM, Wong TY. Interventions for branch retinal vein occlusion: an evidencebased systematic review. Ophthalmology 2007; 114(5): 835-854.

21 Mohamed Q, McIntosh RL, Saw SM, Wong TY. Interventions for central retinal vein occlusion: an evidence-based systematic review. Ophthalmology 2007; 1143(507-519): 524.

22 Brown DM, Campochiaro PA, Singh RP, Li Z, Gray S, Saroj $\mathrm{N}$ et al. Ranibizumab for macular edema following central retinal vein occlusion: six-month primary end point results of a phase III study. Ophthalmology 2010; 117(6): 1124-1133 e1121.

23 Campochiaro PA, Heier JS, Feiner L, Gray S, Saroj N, Rundle AC et al. Ranibizumab for macular edema following branch retinal vein occlusion: six-month primary end point results of a phase III study. Ophthalmology 2010; 117(6): 1102-1112 e1101.

24 Kinge B, Stordahl PB, Forsaa V, Fossen K, Haugstad M, Helgesen $\mathrm{OH}$ et al. Efficacy of ranibizumab in patients with macular edema secondary to central retinal vein occlusion: results from the sham-controlled ROCC study. Am J Ophthalmol 2010; 150(3): 310-314.

25 Epstein DL, Algvere PV, von Wendt G, Seregard S, Kvanta A. Benefit from bevacizumab for macular edema in central retinal vein occlusion: twelve-month results of a prospective, randomized study. Ophthalmology 2012; 119(12): 2587-2591.

26 Kurihara T, Westenskow PD, Bravo S, Aguilar E, Friedlander M. Targeted deletion of Vegfa in adult mice induces vision loss. I Clin Invest 2012; 122(11): 4213-4217.
27 Lohi J, Lehti K, Westermarck J, Kahari VM, Keski-Oja J. Regulation of membrane-type matrix metalloproteinase-1 expression by growth factors and phorbol 12-myristate 13-acetate. Eur J Biochem 1996; 239(2): 239-247.

28 Funk M, Kriechbaum K, Prager F, Benesch T, Georgopoulos M, Zlabinger GJ et al. Intraocular concentrations of growth factors and cytokines in retinal vein occlusion and the effect of therapy with bevacizumab. Invest Ophthalmol Vis Sci 2009; 50(3): 1025-1032.

29 Caprara C, Grimm C. From oxygen to erythropoietin: relevance of hypoxia for retinal development, health and disease. Prog Retin Eye Res 2011; 31(1): 89-119.

30 Inomata Y, Hirata A, Takahashi E, Kawaji T, Fukushima M, Tanihara $\mathrm{H}$. Elevated erythropoietin in vitreous with ischemic retinal diseases. Neuroreport 2004; 15(5): 877-879.

31 Takagi H, Watanabe D, Suzuma K, Kurimoto M, Suzuma I, Ohashi $\mathrm{H}$ et al. Novel role of erythropoietin in proliferative diabetic retinopathy. Diabetes Res Clin Pract 2007; 77 (Suppl 1): S62-S64.

32 Stahl A, Buchwald A, Martin G, Junker B, Chen J, Hansen LL et al. Vitreal levels of erythropoietin are increased in patients with retinal vein occlusion and correlate with vitreal VEGF and the extent of macular edema. Retina 2010; 30(9): 1524-1529.

$33 \mathrm{Yu}$ XB, Sun XH, Dahan E, Guo WY, Qian SH, Meng FR et al. Increased levels of transforming growth factor-betal and -beta2 in the aqueous humor of patients with neovascular glaucoma. Ophthalmic Surg Lasers Imaging 2007; 38(1): 6-14.

34 De La Paz MA, Itoh Y, Toth CA, Nagase H. Matrix metalloproteinases and their inhibitors in human vitreous. Invest Ophthalmol Vis Sci 1998; 39(7): 1256-1260.

35 Jin M, Kashiwagi K, Iizuka Y, Tanaka Y, Imai M, Tsukahara S. Matrix metalloproteinases in human diabetic and nondiabetic vitreous. Retina 2001; 21(1): 28-33.

36 Noda K, Ishida S, Inoue M, Obata K, Oguchi Y, Okada Y et al. Production and activation of matrix metalloproteinase-2 in proliferative diabetic retinopathy. Invest Ophthalmol Vis Sci 2003; 44(5): 2163-2170.

37 Loukovaara S, Robciuc A, Holopainen JM, Lehti K, Pessi T, Liinamaa $J$ et al. Ang-2 upregulation correlates with increased levels of MMP-9, VEGF, EPO and TGFbeta1 in diabetic eyes undergoing vitrectomy. Acta Ophthalmol 2012; 91(6): 531-539. 